\title{
O padrão entoacional das sentenças neutras do português falado em São Tomé: uma análise preliminar
}

\author{
Gabriela Braga \\ Universidade de São Paulo (USP), São Paulo, São Paulo, Brasil \\ gabraga.g@gmail.com
}

DOI: http://dx.doi.org/10.21165/el.v46i1.1661

\begin{abstract}
Resumo
O presente trabalho apresenta uma análise preliminar do padrão entoacional das sentenças declarativas neutras do português falado na ilha de São Tomé (PST), em São Tomé e Príncipe, país africano de colonização portuguesa, a fim de traçar semelhanças e diferenças dessa variedade com as demais já estudadas. Para isso, descrevemos a associação de eventos tonais ao contorno entoacional desse tipo de sentença em PST e comparamos nossos resultados com os obtidos para outras variedades de português já descritas na literatura. Concluímos apontando que o PST possui características que o aproximam das variedades de português brasileiro e da variedade falada em Guiné-Bissau, embora o PST apresente características singulares.
\end{abstract}

Palavras-chave: fonologia; prosódia; português de São Tomé.

The intonational pattern of neutral declarative sentences in São Tomé Portuguese: a preliminary analysis

\begin{abstract}
This paper presents a preliminary analysis of the intonational pattern of neutral declarative sentences of Portuguese spoken in São Tomé island (PST), in São Tomé and Príncipe, an African country with Portuguese colonization. It intends to trace differences and similarities between this variety and others Portuguese varieties already studied. Taking this objective into account, we describe the association of tonal events with the intonational contour of PST neutral sentences and compare our results to the results obtained for other Portuguese varieties already described in the literature. We conclude pointing out that PST has characteristics closer to the Guinea-Bissau Portuguese and Brazilian Portuguese varieties, although PST also presents singular features.
\end{abstract}

Keywords: phonology; prosody; São Tomé portuguese.

\section{Introdução}

Este trabalho tem por objetivo descrever e analisar de modo preliminar o padrão entoacional das sentenças declarativas neutras do português falado na ilha de São Tomé (doravante PST), no que diz respeito à associação de eventos tonais ao contorno entoacional desse tipo de sentença, comparando os resultados com os já descritos na literatura para outras variedades de português (europeu, brasileiro e africano).

Denominamos contorno entoacional neutro o contorno entoacional associado às sentenças declarativas neutras, que são aquelas produzidas como se toda a informação contida fosse nova, ou seja, sem condições discursivas especiais associadas a elas (como elemento em foco, tópico ou contexto de produção de sentenças interrogativas). 
Através dos resultados encontrados nesta pesquisa, mostraremos que o PST apresenta muitas características entoacionais semelhantes às encontradas nas variedades de português brasileiro e se aproxima ainda mais da variedade de português de GuinéBissau (doravante PGB), embora apresente especificidades quanto à distribuição de eventos tonais dentro de um sintagma entoacional (I).

Este artigo está organizado da seguinte maneira: além desta introdução, apresentamos brevemente o contexto histórico-social e linguístico de São Tomé e Príncipe, país onde é falada a variedade de português estudada, para que seja possível compreender as especificidades em que tal variedade surgiu e é utilizada. Em seguida, descrevemos o quadro teórico utilizado para a realização da análise e partimos para a descrição da constituição do corpus e da metodologia aplicada para este estudo. Em seguida, descrevemos e analisamos os resultados encontrados para o contorno entoacional das sentenças neutras do PST e comparamos esta variedade com aquelas já descritas em relação à associação de eventos tonais. Por fim, apresentamos as considerações finais acerca dessa análise preliminar.

\section{O contexto histórico-social e linguístico de São Tomé e Príncipe}

Atualmente denominado República Democrática de São Tomé e Príncipe (STP) e tendo aproximadamente 194 mil habitantes (CIA FACTBOOK, 2016), esse pequeno país africano de colonização portuguesa está localizado na região do Golfo da Guiné, próximo à linha do Equador, e é constituído por duas ilhas - a ilha do Príncipe (mais ao norte) e a ilha de São Tomé (onde está localizada a capital do país) - e algumas ilhotas.

As ilhas de São Tomé e Príncipe foram descobertas desabitadas pelos portugueses em 1471. Em 1485, houve a primeira tentativa de povoamento, sem êxito. Apenas em 1493, data da chegada da frota do primeiro capitão-donatário, Álvaro de Caminha, teve início o povoamento da ilha de São Tomé (HAGEMEIJER, 2011).

Há grandes indícios históricos e linguísticos de que os primeiros africanos trazidos como escravos para São Tomé teriam vindo do antigo Reino do Benin (hoje sudeste da Nigéria), dado os laços comerciais e diplomáticos existentes entre esse reino e os portugueses no final do século XV (MOTA, 1976 apud HAGEMEIJER, 2009). Quanto aos primeiros habitantes não africanos da ilha, segundo Holm (1989), em 1493 cerca de 2000 crianças judias foram tomadas de seus pais (expulsos do reino de Castela) e exiladas em São Tomé por D. João II de Portugal, sendo que mais tarde, em 1506, apenas 600 teriam sobrevivido e se casado com africanos. Degredados portugueses também eram enviados para São Tomé e ganhavam mulheres escravas, a quem eram garantidas liberdade, assim como para seus filhos. Hlibowicka-Węglarz (2012) menciona também que no primeiro século de povoamento a ilha recebeu os primeiros colonos portugueses, madeirenses, judeus e cristãos-novos. Contudo, o povoamento das ilhas se deu majoritariamente pela importação de mão de obra escrava de milhares de pessoas da África subsaariana.

Acredita-se que um pidgin tenha se originado na ilha de São Tomé durante os primeiros anos após o descobrimento das ilhas, devido ao contato constante entre portugueses e africanos e às relações por eles traçadas e por ainda não haver na ilha uma atividade econômica em larga escala (cf. HAGEMEIJER, 2009). Esse pidgin teria se nativizado rapidamente entre os descendentes da primeira geração de africanos 
escravizados e originado o proto-crioulo do Golfo da Guiné, do qual se desenvolveram quatro línguas crioulas: santome, angolar, lung'le e fa d'Ambô. Destas, santome, angolar e lung'Ie surgiram nas ilhas de São Tomé e Príncipe e estão presentes no país ${ }^{1}$.

Por volta de 1515, deu-se início o desenvolvimento comercial da produção de cana de açúcar, atividade que exigia maior quantidade de mão de obra e que alterou a dinâmica social e econômica encontrada na ilha até então. Nesse momento, a captura de escravos foi deslocada da região do Benin para o Congo e, pouco depois, para Angola (ALMEIDA, 2008 apud HAGEMEIJER, 2009). É também a partir desse ponto que São Tomé passa a ser um entreposto comercial de escravos no Atlântico.

Em meados do século XIX são introduzidas, no modelo de monocultura, as plantações de café e de cacau em São Tomé e Príncipe. Para tanto, foram trazidos para trabalhar nas roças, em regime de "contratos" (algo que se assemelhava ao tráfíco humano, ainda remanescente da política escravocrata portuguesa), africanos oriundos de Cabo Verde, Angola e Moçambique, países que, assim como São Tomé e Príncipe, eram colônias portuguesas na época. Com eles vieram suas línguas nativas, a saber: o crioulo caboverdiano e variedades de quicongo e quimbundo.

Nascimento (2000 apud ALEXANDRE et al., 2011, p. 19) aponta que a vinda dos trabalhadores contratados (de 1875 a 1975) teria tido um impacto relevante na formação da variedade do português falado em São Tomé, visto que, em número, esses trabalhadores eram superiores à população já existente na ilha e que, ao chegarem, eles adquiriram o português local como L2, e não o crioulo santome. Entretanto, grande parte dos contratados constituíram comunidades isoladas, permanecendo apenas nas roças e tendo contato limitado com a população da ilha, de modo que, atualmente, o português falado nas roças possui características específicas que o diferem do dito português de São Tomé, sendo na maioria das vezes denominado português dos tongas. Segundo Rougé (2013, p. 64-65), os tongas, descendentes dos contratados provenientes de Angola e Moçambique, falam "um conjunto de variedades de português não padrão, originadas da aprendizagem e da transmissão informais desta língua", além de "variedades de línguas do grupo banto, sobretudo o quimbundo, o umbundo e línguas de Moçambique".

O português é a língua oficial do país desde 1975 (ano da independência de Portugal), sendo a norma lusitana (PE) ensinada nas escolas e considerada como norma de prestígio pela população. A variedade lusitana também está presente na mídia escrita e falada, seja nos telejornais português e local ou nas transmissões de rádio. Entretanto, outras variedades também possuem espaço no país, como o português brasileiro (doravante $\mathrm{PB}$ ), presente nas novelas e alguns programas familiares, o português santomense, falado na ilha de São Tomé (PST), e o português falado na ilha do Príncipe (PPr), que aparece apenas em entrevistas e nas participações do público.

Além do português, estão presentes no país: o santome (também denominado "forro"”) (FERRAZ, 1979; ARAÚJO, 2007; HAGEMEIJER, 2009, 2011; entre outros), o angolar, falado por pescadores do sul da ilha de São Tomé, descendentes de escravos que fugiram das plantações, ainda no século XVI (MAURER, 1995; entre outros), o

\footnotetext{
${ }^{1}$ Embora o fa d'Ambô seja uma das línguas advindas do proto-crioulo do Golfo da Guiné, ela é falada apenas na ilha de Ano Bom, que atualmente faz parte do território da Guiné Equatorial.

2 "Forro" é uma das denominações para o santome, língua crioula mais falada no país. Ela também pode aparecer como "Fôlô", "Lungwa santome", "dialeto" ou "são-tomense".
} 
lung'Ie ${ }^{3}$ (MAURER, 2009; AGOSTINHO, 2014; entre outros), o caboverdiano, o português dos Tongas (BAXTER, 2002; HAGEMEIJER, 2009; entre outros) e resquícios de línguas africanas do grupo banto (HAGEMEIJER, 2009).

O santome, língua crioula mais falada no país, é utilizado majoritariamente em situações informais e por pessoas mais velhas. Além disso, é possível notar cada vez mais a influência moderna do português nessa língua, seja através de inserção de fonemas (como / $\mathrm{r} /$, inicialmente inexistente no santome, mas que começa a ser realizado pelos falantes devido à influência do português) ou de empréstimos lexicais. Alexandre et al. (2011) afirma que, em São Tomé e Príncipe, o português está passando por um acelerado processo de nativização, sobretudo entre os mais jovens. Em entrevistas realizadas com jovens são-tomenses em 2015 para a realização deste estudo, foram coletados relatos de que os pais, desde a geração da independência do país (1975) e cada vez mais, não estão transmitindo as línguas nacionais para os filhos, especialmente nas parcelas mais ricas da sociedade. O santome é adquirido pelas novas gerações de maneira passiva, visto que a língua passou a ser utilizada apenas entre pais e avós daquela geração. Além disso, nos dias atuais, a interação linguística entre pais e filhos utilizando o santome praticamente resume-se a vocativos e expressões para chamar as crianças ou repreendê-las. Em contrapartida, a variedade de português falada em São Tomé (PST) passa a ser L1 de grande parte da população jovem.

Em São Tomé, portanto, acreditamos lidar com as seguintes situações:

1) O contato da língua do português colonizador, dono das roças e senhor de escravos, com as línguas dos escravos trazidos do Níger-congo fez emergirem línguas crioulas;

2) O português manteve-se nas ilhas como a língua do dominador, sendo aprendida como L2 pela população, na busca de ascensão social. Com a independência do país, começa-se a notar o abandono das línguas crioulas em favor do português, que atualmente é aprendido como a única L1 por grande parte da população.

Nossa hipótese é que um caminho novo está sendo seguido, em que as línguas crioulas existentes na ilha entram em contato com o português como línguas de interferência, gerando assim uma nova variedade dessa língua no país, distante da variedade padrão de PE.

\section{Quadro Teórico}

\section{Fonologia Entoacional}

Este trabalho utiliza o aparato teórico da Fonologia Entoacional Autossegmental Métrica, especificamente a proposta de Ladd (2008), para a realização da análise entoacional. Tal abordagem se insere na linha de análise da entoação em níveis de altura tonal, utilizada inicialmente por Pierrehumbert (1980). A teoria tem como principal objetivo identificar os elementos contrastivos da estrutura entoacional e fornecer ferramentas que sejam capazes de descrever universalmente as gramáticas entoacionais das línguas naturais.

\footnotetext{
${ }^{3}$ Lung'Ie é uma das línguas crioulas do país mais falada na ilha do Príncipe, onde surgiu. Pode aparecer também como "Lunguié" e "Principense".
} 
De acordo com Ladd (2008), a entoação apresenta uma organização fonológica própria, de modo que um contorno entoacional se constitui, fonologicamente, de uma sequência de unidades discretas, denominadas eventos tonais, que por sua vez se formam a partir de dois níveis de altura distintos, ou tons primitivos: alto $(\mathrm{H}-$ high $)$ ou baixo (L - low). Essa sequência de eventos tonais, por sua vez, é realizada foneticamente através das curvas da frequência fundamental ( $\mathrm{F}_{0}$ do sinal acústico). De maneira geral, assume-se que os eventos tonais são definidos localmente, um em relação ao anterior, de modo que se considera suficiente o uso de somente dois tons, conforme mencionado, para a descrição dos contornos, mesmo sendo ampla a variação de altura de $\mathrm{F}_{0}$. Ademais, assume-se também que os eventos tonais formam blocos de contorno e estão associados a pontos específicos na cadeia segmental.

Para as variedades de português já estudadas dentro dessa perspectiva teórica (cf., entre outros, FROTA; VIGÁRIO, 2000; VIGÁRIO; FROTA, 2003; CRUZ, 2013; FROTA, 2014; FROTA et al., 2015, para variedades de PE; CUNHA, 2000; FROTA; VIGÁRIO, 2000; TENANI, 2002; FERNANDES, 2007a; 2007b; TRUCKENBRODT; SÂNDALO; ABAURRE， 2009; VIGÁRIO; FERNANDES-SVARTMAN, 2010; FROTA et al., 2015, para variedades de PB; SANTOS; FERNANDES-SVARTMAN, 2014; SANTOS, 2015, para português da Guiné-Bissau), observou-se que os eventos tonais de maior relevância para a descrição da variação da cadeia tonal são os acentos tonais e os tons que estão relacionados às fronteiras. Os acentos tonais são associados às sílabas proeminentes da cadeia segmental, ou seja, a mudança de altura tonal tem como alvo a sílaba portadora de acento lexical. Os acentos tonais podem ser simples, ou seja, monotonais $\left(\mathrm{L}^{*}\right.$ ou $\left.\mathrm{H}^{*}\right)$, ou complexos, bitonais $\left(\mathrm{H}^{*}+\mathrm{L}, \mathrm{H}+\mathrm{L}^{*}, \mathrm{~L}^{*}+\mathrm{H}\right.$ ou $\left.\mathrm{L}+\mathrm{H}^{*}\right)$. Já os tons que se relacionam às fronteiras são associados às fronteiras de domínios prosódicos, ou seja, a mudança de altura tonal tem como alvo uma fronteira de constituinte (HAYES; LAHIRI, 1991). Os tons que se relacionam às fronteiras podem ser de dois tipos: acentos frasais $\left(\mathrm{L}^{-}\right.$ou $\left.\mathrm{H}^{-}\right)$, que se associam às fronteiras de constituintes prosódicos mais baixos que o sintagma entoacional; e tons de fronteira $(\mathrm{L} \%$ ou $\mathrm{H} \%)$, que podem se associar às fronteiras de sintagmas entoacionais (PIERREHUMBERT, 1980).

Além dessas anotações tradicionalmente usadas, os tons marcados como $\mathrm{H}$ podem vir acompanhados de diacríticos: '!' para processos de downstep, e 'i' para processos de upstep. O primeiro indica que um tom $\mathrm{H}$ está sendo realizado relativamente mais baixo do que o tom $\mathrm{H}$ que o precede; já o segundo indica que um tom $\mathrm{H}$ está sendo realizado relativamente mais alto do que o tom $\mathrm{H}$ realizado anteriormente. De acordo com Ladd (2008, p. 77), em algumas línguas africanas o segundo tom $\mathrm{H}$ de uma sequência $\mathrm{H}$ L H pode ser realizado em um nível mais baixo do que o primeiro $\mathrm{H}$, se configurando como $\mathrm{H} \mathrm{L} ! \mathrm{H}$, sendo o nível desse último $\mathrm{H}$ o novo parâmetro de altura para a realização dos próximos Hs que estejam sendo realizados dentro de um determinado constituinte prosódico.

Dentro do quadro teórico da Fonologia Entoacional, adotamos a perspectiva de análise entoacional que prevê a integração entre domínios prosódicos e entoação (cf. HAYES; LAHIRI, 1991; FROTA, 2000; TENANI, 2002). Conforme essa abordagem, a associação de eventos tonais à cadeia segmental é dependente das relações de constituência e proeminência definidas pela estrutura prosódica. Para as variedades de português já estudadas de acordo com essa perspectiva teórica, a estrutura prosódica relevante para a entoação é oferecida pela Hierarquia Prosódica, conforme exposto a 
seguir (cf., entre outros, FROTA, 2000, para PE; TENANI, 2002; FERNANDES, 2007a, b, para PB; e SANTOS, 2015, para PGB).

\title{
Fonologia Prosódica
}

De acordo com a Fonologia Prosódica, assume-se que a estrutura fonológica se relaciona com outros níveis da gramática para a formação de seus constituintes, de maneira que a fala humana se organiza hierarquicamente em constituintes prosódicos que, por sua vez, são formados a partir das informações acessadas através de constituintes sintáticos (SELKIRK, 1984; NESPOR; VOGEL, 1986). Tal relação traçada entre fonologia e a sintaxe é parcialmente determinada, ou seja, não há necessariamente uma correspondência entre a estrutura dos constituintes prosódicos e os constituintes sintáticos, podendo estes coincidir ou divergir. De acordo com a teoria, o mapeamento sintático-fonológico fornece uma representação prosódica em hierarquia de constituintes. Cada nível hierárquico é composto por uma ou mais unidades prosódicas do nível imediatamente inferior. Seguindo a perspectiva de Nespor e Vogel (1986), a hierarquia prosódica é composta por sete domínios, que se organizam conforme a representação a seguir ${ }^{4}$ :

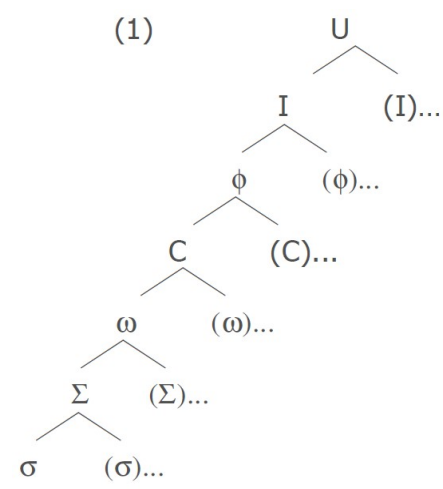

\author{
Enunciado (Utterance) \\ Sintagma Entoacional (Intonational Phrase) \\ Sintagma Fonológico (Phonological Phrase) \\ Grupo Clítico (Clitic Group) \\ Palavra Fonológica (Phonological Word) \\ Pé (Foot) \\ Sílaba (Syllable)
}

Figura 1. Representação da Hierarquia Prosódica, segundo Nespor e Vogel (1986)

A observação do funcionamento de certos processos fonológicos segmentais, rítmicos e tonais (como regras de sândi externo e haplologia sintática, de retração de acento, atribuição de tons e alongamento de fronteiras), em diversas línguas naturais, fornecem evidências de que a fala se organiza hierarquicamente em constituintes prosódicos, visto que tais processos fonológicos ocorrem no interior e entre os limites de certos domínios prosódicos ao mesmo tempo em que podem ser bloqueados em outros (cf. FROTA, 2000).

Nesta análise preliminar, são considerados os domínios da palavra prosódica $(\omega)$, do sintagma fonológico $(\phi)$ e do sintagma entoacional (I), visto que em outras variedades de português (PE, PB e PGB) que serão levadas em conta na comparação com o PST, esses são os domínios prosódicos majoritariamente relevantes na associação de eventos tonais ao contorno entoacional das sentenças neutras.

\footnotetext{
${ }^{4}$ Intonational Phrase e Phonological Phrase aparecem traduzidos, em alguns estudos na literatura linguística brasileira sobre Fonologia Prosódica, como "frase entoacional" e "frase fonológica". Entretanto, neste trabalho traduzimos tais constituintes como "sintagma entoacional" e "sintagma fonológico", respectivamente, visto que o termo phrase, em inglês, refere-se sintaticamente a um sintagma, uma unidade menor que a frase.
} 
Para a formação dos domínios prosódicos em português, assume-se, em linhas gerais, que $\omega$ é o domínio prosódico em que pode haver um único acento primário (ou lexical) (cf. VIGÁRIO, 2003). Por sua vez, $\phi$ corresponde ao domínio que abrange um núcleo lexical e todos os elementos funcionais de seu lado não recursivo ${ }^{5}$ que ainda estejam dentro da projeção máxima de tal núcleo; além disso, ele pode abranger (opcionalmente) o sintagma subsequente que seja complemento não ramificado desse mesmo núcleo lexical (cf. FROTA, 2000). Já o domínio de I consiste em: (i) todos os $\phi s$ em uma sequência que não esteja incorporada estruturalmente à árvore da sentença; (ii) toda sequência de $\phi \mathrm{s}$ adjacentes pertencentes a uma sentença raiz; (iii) um contorno entoacional, cujas fronteiras coincidam com a posição nas quais pausas gramaticais podem ser inseridas em um enunciado (cf. FROTA, 2000).

\section{Corpus e Metodologia}

O corpus desta investigação é constituído por 76 sentenças declarativas neutras adaptadas ao PST com o auxílio de falantes nativos dessa variedade de português, a partir de dados em PE dos corpora constantes na base de dados de línguas românicas, o RLD - Romance Languages Database (para uma descrição completa do RLD, cf. D'IMPÉRIO et al., 2005), que tem sido utilizada para a investigação da variação do fraseamento entoacional das línguas românicas, realizada pelo projeto internacional Intonational Phrasing in Romance ${ }^{6}$.

As sentenças adaptadas do RLD utilizadas como corpora desta pesquisa são constituídas por uma única oração de ordem SVO (sujeito-verbo-objeto), que variam de modo progressivo quanto ao seu tamanho (medido em número de sílabas, incluindo determinantes e preposições), e à complexidade sintático-prosódica (ausência/presença de ramificações, em termos de quantidade de núcleos lexicais e de palavras prosódicas) dos constituintes, como em "A mulher loira manuseava liras na mala". Tal medida é tomada para que sejam observadas possíveis influências das ramificações prosódicas e sintáticas no que diz respeito à associação de eventos tonais ao contorno entoacional das sentenças neutras do PST. Observa-se também que o léxico que constitui tais sentenças é formado por palavras não oxítonas e cuja constituição não apresente segmentos obstruintes e desvozeados, o que poderia gerar uma curva entoacional com perturbações microprosódicas, que dificultariam a análise entoacional.

A metodologia utilizada para a coleta de dados consistiu na tarefa de leitura das sentenças que constituem o corpus, ordenadas aleatoriamente e intercaladas com sentenças distratoras. Cada informante repetiu três vezes o conjunto de sentenças (formado pelas sentenças do corpus e pelas sentenças distratoras). Todas as gravações foram realizadas com o uso de um gravador digital MARANTZ, modelo PMD660, a

\footnotetext{
${ }^{5}$ Sintaticamente, atesta-se que as línguas românicas possuem recursividade à direita.

6 O projeto internacional Intonational Phrasing in Romance (cf. http://www.fl.ul.pt/LaboratorioFonetica/IntPhraRo.htm) tem como objetivos principais: (a) a constituição de uma base de dados de línguas românicas que permita o estudo comparativo da constituência entoacional destas línguas; (b) a descrição e análise da constituência prosódica, levando em consideração o peso de fatores fonético-fonológicos e morfossintáticos; e (c) a compreensão da variação encontrada nas línguas românicas, no domínio da constituência entoacional. Para os resultados já obtidos pelo projeto, conferir, entre outros, Vigário e Frota (2003), Elordieta, Frota e Vigário (2005), D'Império et al. (2005) e Frota e Vigário (2007).
} 
uma frequência de $48.000 \mathrm{~Hz}$, em canal monofônico, e microfone externo SENNHEISER, modelo EW122-P G3.

Esta análise preliminar contempla os dados gravados por duas informantes do sexo feminino, MAQJ e NDR, santomenses, com faixa etária entre 20 e 27 anos, com perfil linguístico semelhante (falantes nativas de PST) e residentes em Redenção/CE há menos de 15 meses, onde são universitárias dos cursos da UNILAB ${ }^{7}$.

O material de áudio obtido nas gravações foi submetido ao software de análise de fala Praat (BOERSMA; WEENINK, 2014), que gerou o espectrograma e a forma de onda do contorno da frequência fundamental $\left(\mathrm{F}_{0}\right)$ das sentenças do corpus. A partir disso, realizou-se a descrição entoacional das sentenças produzidas pelas informantes, compreendendo a identificação e transcrição dos eventos tonais associados ao contorno entoacional das sentenças, tendo como base a percepção auditiva e a exploração do sinal acústico de $\mathrm{F}_{0}$, de acordo com pressupostos teóricos da Fonologia Entoacional.

\section{Resultados e Análise}

\section{Resultados encontrados para o padrão entoacional das sentenças neutras do PST}

Para este estudo preliminar, foram analisadas 411 sentenças neutras, produzidas por MAQJ e NDR. Inicialmente, as informantes selecionadas produziram 456 sentenças (76 sentenças $\mathrm{x}$ três repetições $\mathrm{x}$ dois falantes). Entretanto, 17 sentenças produzidas por MAQJ e 28 sentenças produzidas por NDR foram descartadas por não apresentarem uma leitura fluente ${ }^{8}$ (de acordo com os critérios estabelecidos pelo $\operatorname{In} A P o P^{9}$ ), ou por não serem realizadas de forma neutra, ficando disponíveis para análise 211 sentenças realizadas por MAQJ e 200 sentenças realizadas por NDR.

A partir da análise das sentenças produzidas por essas duas informantes, ilustramos a seguir as características majoritárias para o contorno entoacional das sentenças neutras do PST encontradas nos dados. Em (1), temos uma sentença declarativa neutra realizada por MAQJ; em (2), temos o mapeamento da mesma sentença em constituintes prosódicos e a transcrição dos eventos tonais associados ao contorno entoacional dessa sentença; e, na Figura 2, podemos visualizar o contorno de

\footnotetext{
7 A Universidade da Integração Internacional da Lusofonia Afro-Brasileira - UNILAB (cf. http://www.unilab.edu.br) foi fundada em 2010 pelo governo federal brasileiro para desenvolver a integração entre Brasil e demais países da Comunidade dos Países de Língua Portuguesa (CPLP), em especial, os países africanos. A instituição recebe periodicamente alunos oriundos de Angola, Moçambique, Cabo Verde, São Tomé e Príncipe, Guiné-Bissau e Timor-Leste, além de alunos brasileiros, que ocupam cerca de $50 \%$ das vagas.

${ }^{8}$ No âmbito do InAPoP, consideram-se como de "leitura fluente" as sentenças realizadas sem pausas de hesitação, apagamentos, interrupções, inserções, repetições, ou quaisquer outros eventos que caracterizam marcadores discursivos.

${ }^{9}$ O projeto internacional "Atlas Interativo da Prosódia do Português" (Interactive Atlas of the Prosody of Portuguese - InAPoP) - processo FCT PTDC/CLE-LIN/119787/2010), sob coordenação da Profa. Dra. Sonia Frota e em desenvolvimento na Universidade de Lisboa (Portugal), tem como objetivos principais: (i) o desenvolvimento de pesquisas e aplicações no domínio da prosódia, do ritmo e da entoação no âmbito de um programa de escopo internacional, que propõe um sistema de análise prosódica de corpora de fala, juntamente com um conjunto de procedimentos metodológicos que permitem o trabalho com a variação prosódica da linguagem; e (ii) a criação de um Atlas Interativo da Prosódia do Português online (http://www.fl.ul.pt/LaboratorioFonetica/IntPhraRo.htm), englobando o português europeu integralmente, variedades do português brasileiro e variedades do português africano.
} 
$\mathrm{F}_{0}$ associado à mesma sentença, assim como a marcação, por nós realizada, dos eventos tonais:

(1) "A mulher loira manuseava liras na mala".

(2) $\quad[[($ a muLHER $) \omega($ LOIra $) \omega] \phi[($ manuseAva $) \omega($ LIras $) \omega] \phi[($ na MAla $) \omega] \phi] \mathrm{I}^{10}$
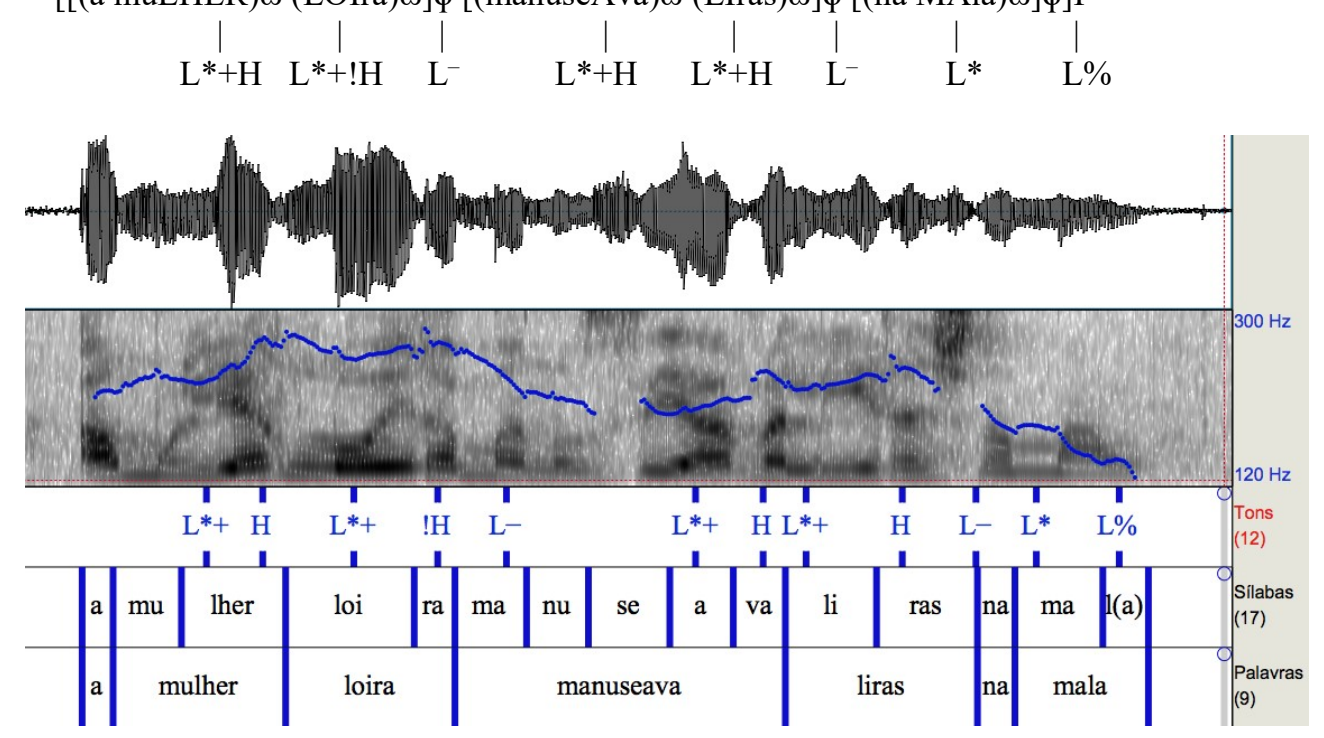

Figura 2. Análise entoacional da sentença "A mulher loira manuseava liras na mala", produzida por MAQJ

Através da síntese do sinal acústico da sentença em (1) realizada pelo software Praat (BOERSMA; WEENINK, 2014) e apresentada na Figura 2, é possível averiguar:

(i) a presença de acentos tonais alinhados às sílabas tônicas de cada palavra fonológica da sentença: um acento tonal $\mathrm{L}^{*}+\mathrm{H}$ associado às palavras fonológicas (a muLHER) $\omega$; (manuseAva) $\omega$ e (LIras) $\omega$; um acento tonal $\mathrm{L}^{*+}$ !H associado à palavra fonológica (LOIra) $\omega$; e um acento tonal $\mathrm{L}^{*}$ associado à palavra fonológica (na MAla);

(ii) a presença de acentos tonais associados às palavras fonológicas cabeças ${ }^{11} \mathrm{de}$ cada sintagma fonológico apresentado: um acento tonal $\mathrm{L}^{*}+\mathrm{H}$ associado à palavra fonológica cabeça do sintagma fonológico [a mulher loira] $\phi$; um acento tonal $\mathrm{L}^{*}+\mathrm{H}$ associado à palavra fonológica cabeça do sintagma fonológico [manuseava liras] $\phi$; e um acento tonal $\mathrm{L}^{*}$ associado à palavra fonológica cabeça do sintagma fonológico [na mala $] \phi ;^{12}$

(iii) a presença de um acento frasal $\mathrm{L}^{-}$associado à fronteira direita do sintagma fonológico longo ${ }^{13}$ ramificado, formado por cinco sílabas [a mulher loira] $\phi$, no qual o sujeito da sentença é mapeado; e a presença de um acento frasal $\mathrm{L}^{-}$associado à fronteira direita do sintagma fonológico longo [manuseava liras] $\phi$, formado por sete sílabas, que compõem parte do predicado da sentença; e

\footnotetext{
${ }^{10}$ As sílabas em letras maiúsculas indicam as sílabas tônicas; as palavras fonológicas estão delimitadas por parênteses; os sintagmas fonológicos e o sintagma entoacional estão delimitados por colchetes.

${ }^{11}$ Nas línguas que possuem recursividade à direita, atesta-se como 'cabeça' do constituinte prosódico o elemento mais à direita.

${ }^{12}$ A palavra fonológica cabeça de cada sintagma fonológico aparece sublinhada.

${ }^{13}$ Considera-se como sintagma fonológico longo aquele que seja formado por quarto sílabas ou mais.
} 
(iv) a presença de um acento tonal $\mathrm{L}^{*}$ associado à palavra fonológica cabeça do último sintagma fonológico [na mala] $\phi$ da sentença e um tom de fronteira $\mathrm{L} \%$ associado à fronteira direita do sintagma entoacional.

Os resultados parciais encontrados, conforme ilustramos acima, mostram que há acentos tonais $\left(\mathrm{T}^{*}\right)$ associados a todas as palavras fonológicas $(\omega)$ das sentenças declarativas neutras do PST, havendo, portanto, uma obrigatoriedade na associação de acentos tonais às palavras fonológicas cabeça e não cabeça de sintagma fonológico $(\phi)$. $\mathrm{Na}$ Tabela 1, podemos verificar a referida obrigatoriedade através da frequência de associação de acentos tonais $\left(\mathrm{T}^{*}\right)$ de acordo com a relevância dos constituintes prosódicos no contorno entoacional das sentenças neutras do PST:

Tabela 1. Frequência de atribuição de acentos tonais ( $\left.T^{*}\right)$ de acordo com a relevância dos constituintes prosódicos no contorno entoacional das sentenças declarativas neutras do PST

\begin{tabular}{l|c|c}
\hline Constituinte prosódico & Constituinte com $T^{*}$ associado & Constituinte sem T* associado \\
\hline$\omega(1830)$ & $1830(100 \%)$ & - \\
\hline$\omega$ não cabeça de $\phi(431)$ & $431(100 \%)$ & - \\
\hline$\omega$ cabeça de $\phi(1399)$ & $1399(100 \%)$ & - \\
\hline$\omega$ cabeça do último $\phi$ de I $(411)$ & $411(100 \%)$ & - \\
\hline
\end{tabular}

A análise do corpus nos mostrou que os acentos tonais associados às palavras fonológicas $(\omega)$ não cabeça de sintagma fonológico $(\phi)$ são majoritariamente bitonais, de configuração $L^{*}+\mathrm{H}$, ocorrendo em $97,2 \%$ desses casos. Em menor ocorrência (apenas $2 \%$ ), aparece a associação do acento monotonal $\mathrm{L}^{*}$ às palavras fonológicas não cabeça de $\phi$, e apenas em $0,8 \%$ das palavras fonológicas não cabeça de $\phi$ há a associação do acento monotonal $\mathrm{H}^{*}$. Tal frequência demonstra que há uma preferência pela associação de acentos tonais ascendentes $\left(\mathrm{L}^{*}+\mathrm{H}\right)$ ao contorno entoacional não final das sentenças neutras do PST. Não foi encontrada, porém, associação de tom adicional ao longo do contorno entoacional das sentenças analisadas.

Com relação ao contorno nuclear, foi encontrada majoritariamente a associação do acento tonal $\mathrm{L}^{*}$ à palavra fonológica $(\omega)$ cabeça do último sintagma fonológico $(\phi)$ do sintagma entoacional $(81,3 \%$ das sentenças analisadas), enquanto que o acento bitonal $\mathrm{H}+\mathrm{L}^{*}$ aparece associado à palavra fonológica cabeça do último $\phi$ do sintagma entoacional em $18,7 \%$ dos dados verificados.

No que tange ao tom de fronteira (T\%), a Tabela 2 a seguir traz a sua frequência de associação ao contorno entoacional das sentenças declarativas neutras do PST:

Tabela 2. Frequência de associação de tom de fronteira (T\%) ao contorno entoacional das sentenças declarativas neutras do PST

\begin{tabular}{l|c|c}
\hline Contexto prosódico & Contexto com T\% associado & Contexto sem T\% associado \\
\hline Fronteira direita de I (411) & $403(98,1 \%)$ & $8(1,9 \%)$ \\
\hline
\end{tabular}

Conforme apresentamos na Tabela 2, em $98,1 \%$ das sentenças analisadas, foi verificada a associação de um tom de fronteira $(\mathrm{T} \%)$ à fronteira direita do sintagma entoacional, sendo que, em todos os casos, esse tom de fronteira encontrado foi um tom baixo, L\%. Nas sentenças em que não foram encontrados tons de fronteira associados à fronteira direita de I, percebe-se que as sílabas pós-tônicas das palavras cabeça do último sintagma fonológico $(\phi)$ de I não foram realizadas plenamente, não havendo, 
portanto, contorno entoacional associado a elas, o que pode ter acarretado na não manifestação de um tom de fronteira. Desse modo, há um forte indício de que as sentenças neutras do PST possuam, como contorno nuclear de $\mathrm{I}$, a configuração L* L\%, embora o contorno $\mathrm{H}+\mathrm{L}^{*} \mathrm{~L} \%$ também seja possível nessa variedade de português para esse tipo de sentença.

Ademais, foi verificada a possibilidade de associação de acentos frasais $\mathrm{L}^{-}$à fronteira direita de sintagmas fonológicos não finais de sintagma entoacional. Os resultados encontrados são apresentados na Tabela 3:

Tabela 3. Frequência de associação de acento frasal $\left(T^{-}\right)$ao contorno entoacional das sentenças declarativas neutras do PST

\begin{tabular}{l|c|c}
\hline Contexto prosódico & Contexto com $\mathrm{T}^{-}$associado & Contexto sem $\mathrm{T}^{-}$associado \\
\hline Fronteira direita de $\phi$ não final de I (988) & $129(13,1 \%)$ & $859(86,9 \%)$ \\
\hline
\end{tabular}

Conforme podemos ver na Tabela 3 , a associação de acento frasal $\left(\mathrm{T}^{-}\right)$à fronteira direita de sintagma fonológico $(\phi)$ não final de sintagma entoacional (I) ocorre em apenas $13,1 \%$ das sentenças analisadas. Entretanto, ainda não podemos afirmar com critério o que desencadeia a associação desse evento tonal, embora observe-se que, na maioria dos casos, ele está associado a sintagmas fonológicos longos, sejam eles ramificados ou não, sejam eles sujeito ou predicado da sentença. Estudaremos melhor a associação do acento frasal à fronteira direita de $\phi$ futuramente.

\section{Comparação entre o padrão entoacional das sentenças neutras do PST e as demais variedades de português já estudadas na literatura}

Comparando o padrão entoacional encontrado para as sentenças neutras do PST com os padrões do mesmo tipo de sentença já descritos para outras variedades de português no âmbito do mesmo quadro teórico utilizado neste trabalho, encontramos características que o afastam da variedade falada em Lisboa (SEP) (FROTA; VIGÁRIO, 2000; FROTA, 2014; entre outros), e o aproximam das variedades do norte de Portugal (NEP) (VIGÁRIO; FROTA, 2003; FROTA; VIGÁRIO, 2007; CRUZ, 2013) e do Alentejo (ALE) (CRUZ, 2013), assim como do português falado no Brasil (CUNHA, 2000; FROTA; VIGÁRIO, 2000; TENANI, 2002; FERNANDES, 2007a, 2007b), e mais ainda do português falado em Guiné-Bissau (PGB) (SANTOS; FERNANDES-SVARTMAN, 2014; SANTOS, 2015).

Em relação à distribuição de eventos tonais associados ao contorno entoacional neutro, o PST se distancia muito do SEP, visto que em PST há uma obrigatoriedade na associação de acentos tonais a todas as palavras fonológicas de I, sejam elas cabeça ou não cabeça de sintagma fonológico, enquanto em SEP a distribuição de eventos tonais é esparsa, sendo obrigatória a associação de acento tonal apenas para a palavra fonológica cabeça do último sintagma fonológico de I, visto que o domínio relevante para a associação de acentos tonais na variedade SEP, dentro da hierarquia prosódica, é o do sintagma entoacional (I).

Nesse ponto, o PST vai ao encontro do que ocorre nas demais variedades de português, em especial às variedades de $\mathrm{PB}$ já descritas, cujos domínios relevantes na atribuição de acentos tonais são a palavra fonológica $(\omega)$ e o sintagma fonológico $(\phi)$, e ao PGB, cujo domínio relevante na atribuição de acentos tonais é a palavra fonológica

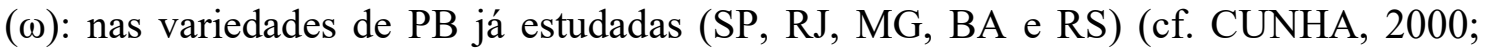


FROTA; VIGÁRIO, 2000; TENANI, 2002; FERNANDES， 2007a， 2007b; TRUCKENBRODT; SÂNDALO; ABAURRE， 2009; VIGÁRIO; FERNANDESSVARTMAN, 2010; FROTA et al., 2015), praticamente todas as palavras fonológicas apresentam associação de acento tonal, embora só exista obrigatoriedade de associação de acento tonal à $\omega$ cabeça de $\phi$; no PGB, há a mesma obrigatoriedade e é possível encontrar acentos tonais associados também a $\omega$ não cabeça de $\phi$ (SANTOS; FERNANDES-SVARTMAN, 2014; SANTOS, 2015), especialmente em sintagmas fonológicos que constituem o predicado da sentença (SANTOS, 2015). Entretanto, o PST se diferencia das variedades de PB em relação à distribuição de eventos tonais por não apresentar um evento tonal adicional: no $\mathrm{PB}$, palavras que possuam mais de 2 sílabas pretônicas podem apresentar associadas a elas um evento tonal $\mathrm{H}$, que, por hipótese, teria ligação com a marcação de acento secundário. A obrigatoriedade da associação de acentos tonais a todas as palavras fonológicas, encontrada nos dados de PST analisados, nos leva a assumir que $\omega$ é o domínio relevante na atribuição de acentos tonais em PST.

No que tange ao contorno nuclear, embora no PST seja possível uma configuração $\mathrm{H}+\mathrm{L}^{*} \mathrm{~L} \%$ (configuração de contorno nuclear encontrada em 18,7\% das sentenças de PST analisadas), semelhante ao que é encontrado para todas as variedades do PB já estudadas (cf. CUNHA, 2000; FROTA; VIGÁRIO, 2000; TENANI, 2002; FERNANDES, 2007a， 2007b; SÂNDALO; ABAURRE， 2009; VIGÁRIO; FERNANDES-SVARTMAN, 2010; FROTA et al., 2015), assim como para as variedades SEP e ALG (Algarve) (cf. entre outros, FROTA; VIGÁRIO, 2000; FROTA, 2014 para SEP, e CRUZ, 2013, para ALG), faladas em Portugal, e majoritariamente em PGB (cf. SANTOS; FERNANDES-SVARTMAN, 2014; SANTOS, 2015), a configuração L* L\% é predominante para o contorno nuclear em PST, ocorrendo em $81,3 \%$ das sentenças analisadas, se aproximando das variedades faladas na região do Alentejo (ALE) e na região de Braga (NEP) (cf. entre outros, CRUZ, 2013, para ALE, e VIGÁRIO; FROTA, 2003; FROTA; VIGÁRIO, 2007; CRUZ, 2013, para NEP), no norte de Portugal, que também apresentam a configuração $\mathrm{L}^{*} \mathrm{~L} \%$ para o contorno nuclear das sentenças declarativas neutras.

Embora a associação de acento frasal à fronteira direita de sintagmas fonológicos não finais nas sentenças neutras do PST ainda precise de maiores investigações, é possível apontar que esta é uma característica que aproxima essa variedade de português a apenas duas outras, a saber: o PGB e o ALE. As demais variedades não apresentam esse tipo de evento tonal associado ao contorno entoacional das sentenças neutras. Com relação ao acento frasal encontrado em ALE, Cruz (2013) afirma que um tom baixo relacionado à fronteira de sintagma fonológico pode estar associado à fronteira esquerda do último sintagma fonológico, anotado pela autora como pL, sendo que tal tom associa-se apenas a essa posição e apenas para essa variedade do ALE, dentre as variedades de PE já estudadas. Já o acento frasal encontrado para o PGB, anotado como L ${ }^{-}$em Santos e Fernandes-Svartman (2014) e em Santos (2015), é encontrado associado às fronteiras direitas dos sintagmas fonológicos que se encontram em diferentes posições do contorno entoacional, conforme afirma Santos (2015), mas há maior incidência de associação a sintagmas fonológicos longos (4 sílabas ou mais), não ramificados prosodicamente e que constituam o sujeito da sentença ou na fronteira que faz a divisão entre sintagmas pertencentes ao sujeito e ao predicado. 
A associação de acento frasal em PST, portanto, se assemelha em muitos aspectos àquela que ocorre em PGB, visto que em PST a associação desse tom de fronteira se dá em sintagmas fonológicos que ocupam diferentes posições dentro da sentença, longos ou curtos, sejam eles ramificados ou não.

\section{Considerações finais}

Através da análise do contorno entoacional das sentenças neutras do PST e da comparação entre os resultados encontrados e os padrões entoacionais das demais variedades de português já descritos na literatura para esse mesmo tipo de sentença, vimos que o PST é uma variedade que se distancia entoacionalmente da variedade standard de português europeu (SEP) em muitos pontos, embora SEP seja a variedade de prestígio em São Tomé e Príncipe, ensinada nas escolas e veiculada na mídia falada e escrita. Encontramos diferenças entre essas duas variedades na distribuição de acentos tonais ao longo do contorno entoacional, na configuração do contorno nuclear, na associação de acento frasal à fronteira direita de sintagmas fonológicos não finais de I e com relação ao domínio prosódico relevante na atribuição de acentos tonais ao longo do contorno entoacional das sentenças declarativas neutras.

Tais observações corroboram em parte nossa hipótese inicial, ao mostrarem que de fato o PST é uma variedade distinta da variedade standard de português europeu (SEP) do ponto de vista entoacional. Estudos futuros, comparando o contorno entoacional do PST com o das línguas crioulas faladas na ilha, em especial o santome, poderão nos mostrar se essa variedade de português sofreu interferência das línguas nacionais na constituição de seu padrão entoacional.

Entretanto, não podemos ignorar que o PST apresenta características entoacionais que o aproximam das variedades de PB e especialmente ao PGB (variedades ultramarinas de português, assim como o PST), como a alta atribuição de eventos tonais associados ao contorno entoacional e o fato de $\omega$ ser o domínio prosódico relevante (um deles, no caso do PB) na atribuição de acentos tonais ao longo do contorno entoacional das sentenças declarativas neutras. Além dessas, PST e PGB se assemelham ainda por apresentarem a possibilidade de associação de um acento frasal à fronteira direita do sintagma fonológico, embora a associação desse tipo de tom relacionado à fronteira ainda necessite de maiores investigações para o PST e também para o PGB. Entretanto, em relação à configuração do contorno nuclear, embora em ambas as variedades sejam encontrados o contorno descendente $\mathrm{H}+\mathrm{L} * \mathrm{~L} \%$ e o contorno baixo $\mathrm{L}^{*} \mathrm{~L} \%$, o PGB parece optar pelo contorno nuclear descendente $\mathrm{H}+\mathrm{L} * \mathrm{~L} \%$ para as sentenças declarativas neutras, enquanto o PST apresenta uma incidência muito maior da configuração $L^{*} \mathrm{~L} \%$ para o contorno nuclear das sentenças neutras.

Os próximos passos da pesquisa caminharão para a ampliação do corpus, analisando dados coletados de mais duas informantes, refinando os resultados parciais apresentados neste trabalho. Além disso, buscaremos investigar as características da associação do acento frasal às fronteiras dos sintagmas fonológicos não finais do contorno entoacional das sentenças declarativas neutras do PST. 


\section{REFERÊNCIAS}

AGOSTINHO, A. L. S. Fonologia e método pedagógico do lung'Ie. 2014. 425 f. Tese (Doutorado em Letras) - Faculdade de Filosofia, Letras e Ciências Humanas, Universidade de São Paulo, São Paulo, 2014.

ALEXANDRE, N. et al. A formação de frases relativas em português oral de Cabo Verde e de São Tomé. In: COSTA, A.; FALÉ, I.; BARBOSA, P. (Eds.). Textos seleccionados do XXVI Encontro Nacional da APL 2010, Lisboa: APL, 2011. p. 17-34.

ARAÚJO, G. A. Empréstimos recentes do português, variação fonética e a sílaba na língua são-tomense da ilha de São Tomé. PAPIA, Brasília, v. 17, p. 55-66, 2007.

BAXTER, A. N. Semicreolization? The restructured Portuguese of the Tongas of São Tomé, a consequence of L1 acquisition in a special contact situation. Journal of Portuguese Linguistics, Lisboa, v. 1, p. 7-39, 2002.

BOERSMA, P.; WEENINK, D. Praat: doing phonetics by computer (Version 5.3.82) Computer Program, 2014. Disponível em: <http://www.praat.org>. Acesso em: 13 jan. 2016.

CIA FACTBOOK. CIA: The world factbook. Disponível em: $<$ https://www.cia.gov/library/publications/the-world-factbook/geos/tp.html $>$. Acesso em: 13 jan. 2016.

CRUZ, M. Prosodic variation in European Portuguese: phrasing, intonation and rhythm in central-southern varieties. 2013. 176 f. Tese (Doutorado em Linguística) Universidade de Lisboa, Lisboa, 2013.

CUNHA, C. S. Entoação regional no português do Brasil. 2000. 201 f. Tese Faculdade de Letras, Universidade Federal do Rio de Janeiro, Rio de Janeiro, 2000.

D'IMPÉRIO, M. et al. Intonational Phrasing in Romance: The role of prosodic and syntactic structure. In: FROTA, S.; VIGARIO, M.; FREITAS, M. J. (Eds.). Prosodies. Phonetics \& Phonology Series. Berlin: Mouton de Gruyter, 2005. p. 59-97.

ELORDIETA, G.; FROTA, S.; VIGÁRIO, M. Subjects, objects and intonational phrasing in Spanish and Portuguese. Studia Linguistica, v. 59, n. 2-3, p. 110-143, 2005.

FERNANDES, F. R. Tonal association in neutral and subject-narrow-focus sentences of Brazilian Portuguese: a comparison with European Portuguese. Journal of Portuguese Linguistics, n. 5-6, p. 91-115, 2007a.

Ordem, focalização e preenchimento em português: sintaxe e prosódia. 2007b. 415 f. Tese (Doutorado em Linguística) - Instituto de Estudos da Linguagem, Universidade Estadual de Campinas, Campinas, 2007b.

FERRAZ, L. I. The creole of São Tomé. Johannesburg: Witwatersrand University Press, 1979.

FROTA, S. Prosody and focus in European Portuguese: phonological phrasing and intonation. New York: Garland Publishing, 2000.

The intonational phonology of European Portuguese. In: JUN, S.-A. (Ed.). Prosodic Typology II. Oxford: Oxford University Press, 2014. p. 6-42. 
FROTA, S. et al. Intonational variation in Portuguese: European and Brazilian varieties. In: FROTA, S.; PRIETO, P. (Eds.). Intonation in Romance. New York: Oxford University, 2015. p. 235-283.

FROTA, S.; VIGÁRIO, M. Aspectos de prosódia comparada: ritmo e entoação no PE e no PB. In: CASTRO, R. V.; BARBOSA, P. (Org.). Actas do XV Encontro Nacional da Associação Portuguesa de Linguística. Coimbra: APL, 2000. v. 1, p. 533-555.

Intonational phrasing in two varieties of European Portuguese. In: RIAD, T.; GUSSENHOVEN, C. (Eds.). Tones and Tunes. v. 1. Berlin: Mouton de Gruyter, 2007. p. 265-291.

HAGEMEIJER, T. As línguas de São Tomé e Príncipe, Revista de Crioulos de Base Lexical Portuguesa e Espanhola, v. 1, p. 1-29, 2009.

. The Gulf of Guinea Creoles: genetic and typological relations, Journal of Pidgin and Creole Languages, v. 26, n. 1, p. 111-154, 2011.

HAYES, B.; LAHIRI, A. Bengali intonational phonology. Natural Language and Linguistic Theory, v. 9, n. 1, p. 47-96, 1991.

HLIBOWICKA-WĘGLARZ, B. A origem dos crioulos de base lexical portuguesa no Golfo da Guiné. Romanica Cracoviensia, Kraków, v. 11, p. 177-185, 2012. Disponível em: $\quad<$ http://www.wuj.pl/UserFiles/File/Romanica\%20Cracoviensia\%202011/23Hlibowicka-RC-2011.pdf>. Acesso em: 28 jun. 2016.

HOLM, J. Pidgins and creoles. v. 2. Cambridge: Cambridge University Press, 1989.

LADD, D. R. Intonational Phonology. Cambridge, Mass.: CUP, 2008 [1996].

MAURER, P. L'Angolar: Un Créole Afro-Portugais parlé à São Tomé. Hamburg: Helmut Buske Verlag, 1995.

. Principense. Grammar, texts, and vocabulary of the Afro-Portuguese creole of the Island of Príncipe, Gulf of Guinea. London: Battlebridge Publications, 2009.

NESPOR, M.; VOGEL, I. Prosodic Phonology. Dordrecht: Foris Publications, 1986.

PIERREHUMBERT, J. The phonology and phonetics of English intonation. 1980. 402 f. Tese (PhD) - MIT, Cambridge, Mass, 1980.

ROUGÉ, J. A inexistência de crioulo no Brasil. In: FIORIN, J. L.; PETTER, M. (Org.). África no Brasil: A formação da língua portuguesa. 2. ed. São Paulo: Contexto, 2013. p. 63-73.

SANTOS, V. G. Entoação do contorno neutro do português de Guiné-Bissau: uma comparação com o português brasileiro. 2015. 226 f. Dissertação (Mestrado em Letras) - Faculdade de Filosofia, Letras e Ciências Humanas, Universidade de São Paulo, São Paulo, 2015.

SANTOS, V. G.; FERNANDES-SVARTMAN, F. R. O padrão entoacional neutro do português de Guiné-Bissau: uma comparação preliminar com o português brasileiro. Estudos Linguísticos, São Paulo, v. 43, p. 48-63, 2014.

SELKIRK, E. O. Phonology and syntax: the relation between sound and structure. Cambridge, Mass.: The MIT. Press, 1984. 
TENANI, L. E. Domínios prosódicos no português. 2002. 317 f. Tese (Doutorado em Linguística) - Instituto de Estudos da Linguagem, Universidade Estadual de Campinas, Campinas, 2002.

TRUCKENBRODT, H.; SÂNDALO, M. F. S.; ABAURRE, M. B. M. Elements of Brazilian Portuguese intonation. Journal of Portuguese Linguistics, v. 8, p. 75-114, 2009.

VIGÁRIO, M. The prosodic word in European Portuguese. Berlin-New York: Mouton de Gruyter, 2003.

VIGÁRIO, M.; FERNANDES-SVARTMAN, F. R. A atribuição de acentos tonais em compostos no português do Brasil. In: BRITO, A. M. et al. (Org.). XXV Encontro da Associação Portuguesa de Linguística: Textos Seleccionados, Porto: Tip. Nunes Ltda., Maia, v. 1, p. 769-786, 2010.

VIGÁRIO, M.; FROTA, S. The intonation of Standard and Northern European Portuguese. Journal of Portuguese Linguistics. Special Issue on Portuguese Phonology edited by W. L. Wetzels, v. 2, n. 2, p. 115-137, 2003.

Recebido em: 30/08/2016

Aprovado em: 28/10/2016 